NAA - SR-165

PAGE I OF 18

COPY \&8 OF 270

$1=$

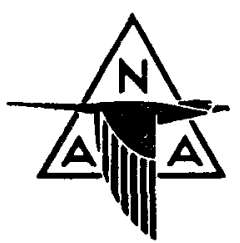

aron

\title{
HIGH TEMPERATURE COMPRESSION TESTS ON GRAPHITE
}

WRITTEN BY:

L. GREEN
This document is PUBLICLY RELEASABLE

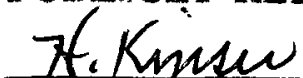
Authosizing Official Date: $2-1-2012$

C. R. MALMSTROM, GROUP LEADER, ENGINEERING LABORATORY

S. SIEGEL-ASSOCIATE DIRECTOR

C. STARR - DIRECTOR

\section{ATOMIC ENERGY RESEARCH DEPARTMENT} NORTHAMERICAN AVIATION, INC. P. O. BOX 309 


\section{DISCLAIMER}

This report was prepared as an account of work sponsored by an agency of the United States Government. Neither the United States Government nor any agency Thereof, nor any of their employees, makes any warranty, express or implied, or assumes any legal liability or responsibility for the accuracy, completeness, or usefulness of any information, apparatus, product, or process disclosed, or represents that its use would not infringe privately owned rights. Reference herein to any specific commercial product, process, or service by trade name, trademark, manufacturer, or otherwise does not necessarily constitute or imply its endorsement, recommendation, or favoring by the United States Government or any agency thereof. The views and opinions of authors expressed herein do not necessarily state or reflect those of the United States Government or any agency thereof. 


\section{DISCLAIMER}

Portions of this document may be illegible in electronic image products. Images are produced from the best available original document. 
This report is distributed according to the category "Metallurgy and Ceramics" as given in the Distribution Lists for United States Atomic Energy Non-Classified Research and Development Reports" TID-4500, July 19, 1951. 


\section{ABSTRACT}

Experiments on the compression of graphite cylinders at temperatures up to about $2600^{\circ} \mathrm{C}$ are described. It is found that the short-time compressive strength increases with temperature in the range from room temperature to $2000 \circ \mathrm{C}$ in a manner paralleling the tensile strength behavior. Typical stressstrain curves are presented, but the limited degree of experimental control dictated by the available test equipment makes the results only semi-quantitative in nature. The large, mutually opposing influences of temperature and strain rate are illustrated by photographs of typical failures.

This report is based upon studies conducted for the Atomic Energy Commission under Contract AT-11-1-GEN-8. 


\section{INTRODUCTION}

The unusual plastic and elastic properties exhibited by graphite under tension, torsion and flexure at elevated temperatures $1,2,3$ aroused interest in its high-temperature behavior under compression. It was desired, for instance, to check the temperature dependence of the short-time breaking strength, since the tensile strength of graphite had been found to increase markedly with temperature up to the point where the influence of creep predominated. At such temperatures, the effect of strain rate was known to be large, and it was desired to study this effect at least qualitatively.

\section{EQUIPNENT AND PROCEDURE}

The specimens used in the compression tests were right circular cylinders of grade AUF* graphite, 0.5 inch in diameter and 1 inch in height. In order to obtain material of maximum uniformity, the specimens were cut from the central 4-inch diameter core of the extruded graphite rod, with their axes parallel to the direction of extrusion.

The apparatus used for the high-temperature testing is diagramed in Fig. I; the graphite specimen was compressed between two water-cooled copper electrodes. The Image of the specimen (heated to incandescence by the passage of a direct current from a 25-kilowatt motor-generator set) was focussed on a ground-glass screen by means of an achromatic lens in one of the furnace windows. End blocks of ungraphitized carbon hindered heat flow away from the specimen and provided regions of high heat-generation rate at its ends, thus holding the longitudinal temperature difference along the specimen to about 2 per cent of the total temperature. A radial temperature gradient existed within the specimen, but, for the purpose of the present preliminary study, the maximum surface temperature (as measured by an optical pyrometer) was taken as the specimen temperature. The tests were conducted in a vacuum of about 30 to 100 microns.

\footnotetext{
* National Carbon Company
} 
The equipment used for compressing the graphite was a laboratory-made testing machine in which the stress was applied by a hydraulic cylinder. $\mathbb{A}$ loading mechanism consisting essentially of a Vickers pump, two Adel flow control valves, and a four-way valve (as shown in Fig. 2) was constructed for this machine in order to permit operation at a variety of loading rates. The hydraulic equipment could not achieve testing at a constant strain rate, however, as is mentioned below. The net force on the specimen was established (with precision suficicient for the present study) by subtracting from the total cylinder pressure that pressure which was required to support the furnace and the moving bed of the testing machine. The cylinder pressure was indicated by two Bourdon gauges, one on the control board and one on the panel containing the ground glass projection screen. Viewing of this panel (on which a clock was also mounted) by a. Bell and Howell 35-millimeter type A-4-A bomb spotting camera provided a photographic record of the specimen deformation as a function of stress and time. Strain was determined by projecting the film with a microfilm viewer and measuring the length of the specimen image with a vernier caliper. A 6-inch steel rule cemented to the ground glass panel served as a reference length for correction of the strain measurements.

\section{RESULTS}

\section{A. Stress-Strain Curves}

Experimentation revealed that stress-strain curves at constant temperature could not be obtained because of the large number of elements in series with the specimen (see Fig. 1). As the stress increased, the contact between the carbon and graphite surfaces became more intimate, the current through the specimen increased and the temperature rose accordingly. This effect could not be eliminated without removing all carbon and graphite elements (except the specimen) between the copper electrodes and thus destroying the uniformity of the temperature distribution along the specimen. Manuel adjustments of the rheostat controlling the generator current could not be made rapidy enough to compensate for the resistance change in the specimen circuit, and so stressstrain curves obtained with increasing temperature were accepted for purpose of qualitative comparison. Two such curves obtained at a fixed head rate but 
at two different initial temperatures are presented in Fig. 3. It is believed that the apparent yield point exhibited by the lower-temperature curve is attributable to the rapid temperature change occurring during the loading and is not an inherent property of the material.

Photographs of the two specimens of Fig. 3 at various periods in their "Iives" are shown in Figs. 4 and 5. In the higher temperature test, where the effects of creep are large, fallure occurs slowly, apparently aided by creep buckling induced by a possible eccentricity of loading, together with local softening of the carbon end blocks. (Reference to Fig. 3 shows that the appearance of the buckling tendency coincided with a drop in the stress-strain curve.) At the lower temperature, by contrast, failure occurred suddenly in the form of brittle fracture, thus producing the flash show in the photograph.

\section{B. Breaking Strength}

In measurements of breaking strength (as well as stress-strain curves) It is desirable to control the testing by carrying out all the measurements at a constant rate of strain or rate of stress increase. No such control was possible in the present work, however, since, in the simple hydraulic loading system used here, the only quantity which could be adjusted was the velocity of the machine bed as determined by the rate of flow into the loading cylinder, and even this decreased slightly as the pressure in the cylinder built up.

The short-time compressive strength of AUF graphite is presented as a function of testing temperature in Fig. 6. The large scatter seen there is attributed to slight density variations ${ }^{I}$ in the specimen and to differences in specimen alignment in the testing machine. It is well known ${ }^{4}$ that the results of axial compression tests are highly sensitive to the degree of constraint of the specimen ends by the two bearing surfaces; special precautions are usually necessary to assure that the lateral extension of all cross sections is the same. In the present high-temperature tests, no lubrication of the bearing surfaces was attempted, and the nonuniformity of stress at the ends of the specimen resulting from friction between the specimen and the carbon end blocks was accepted as an inherent error. In addition, the specimen could not be centered with certainty because of the restricted confines of the furnace, and 
the slight eccentricity of loading which was consequently possible may have contributed to the error. Despite the large scatter shown by the points of Fig. 6, it is apparent that the short-time compressive strength of AUF graphite increases with temperature in a fashion closely paralleling the short-time tensile strength, ${ }^{5}$ data for which are included for comperison. The tensile strength shows a maximum near $2500^{\circ} \mathrm{C}$, where the influence of creep becomes predominant. $^{1}$

\section{TYPES OF FAILURE}

The large influence of strain rate on the mechanical properties of graphite is qualitatively indicated by the above strength results. The apparent strength increases with temperature as long as the rate of strain is large compared to the creep rate. Under such conditions, failure occurs by a fracture of the "brittle" type, examples of which are show in Fig. 7. These fractures are typical of the failures which were obtained at temperatures from $20{ }^{\circ} \mathrm{C}$ to about $2000^{\circ} \mathrm{C}$, a range in which creep did not greatly influence the results. In an attempt to examine further the brittle failure of graphite, the image of a specimen fractured at $2000^{\circ} \mathrm{C}$ was photographed at about 1200 frames/second by a Western Electric "Fostax" 16 millimeter camera. Five consecutive frames from the film are shown in Fig. 8, and it may be seen from the sudden appearance of the slip lines in frame 3 that, despite the elevated temperature, complete failure occurred in less than 1 millisecond.

At high temperatures and Iow rates of strain, however, the specimens deform plasticaliy by creep, which in the case of graphite must be regarded as a diffusion process. 6 Examples of specimens compressed slowly at high

*Graphite apparently does not deform plastically by a slip mechanism, any slip resulting in immediate fracture. In an effort to detect cold-working as a result of short-time plastic deformation, filings of AUF graphite were pulverized by a mortar and pestle and classified by Tyler screens. The $-250+300$ fraction was retained, and half of it was annealed in vacuo at $15000 \mathrm{C}$ for two hours. The annealed and unannealed portions were then subjected to X-ray analysis. Examination by means of a North American Phillips automatic recording goniometer revealed no significant change in the amplitude and shape of several lines of the diffraction pattern as a result of the powder treatment.7 
temperatures are shown in Fig. 9. (The specimen which was compressed at the highest temperature shows a shiny crust which seems to have formed due to an impurity in the carbon end blocks.)

\section{CONCLUSION}

From the results of the experiments described above, it is concluded that the mechanical behavior of graphite is interesting enough to deserve detailed study. The possibility of increasing the apparent density of (porous) commercial graphite by compressing it at a temperature high enough and at a rate slow enough to insure that all the deformation occurs without any local fracturing appears especially attractive, since graphite of a density approaching the maximum theoretical value $\left(2.25 \mathrm{gm} / \mathrm{cm}^{3}\right)$ might exhibit greatly improved strength properties. 


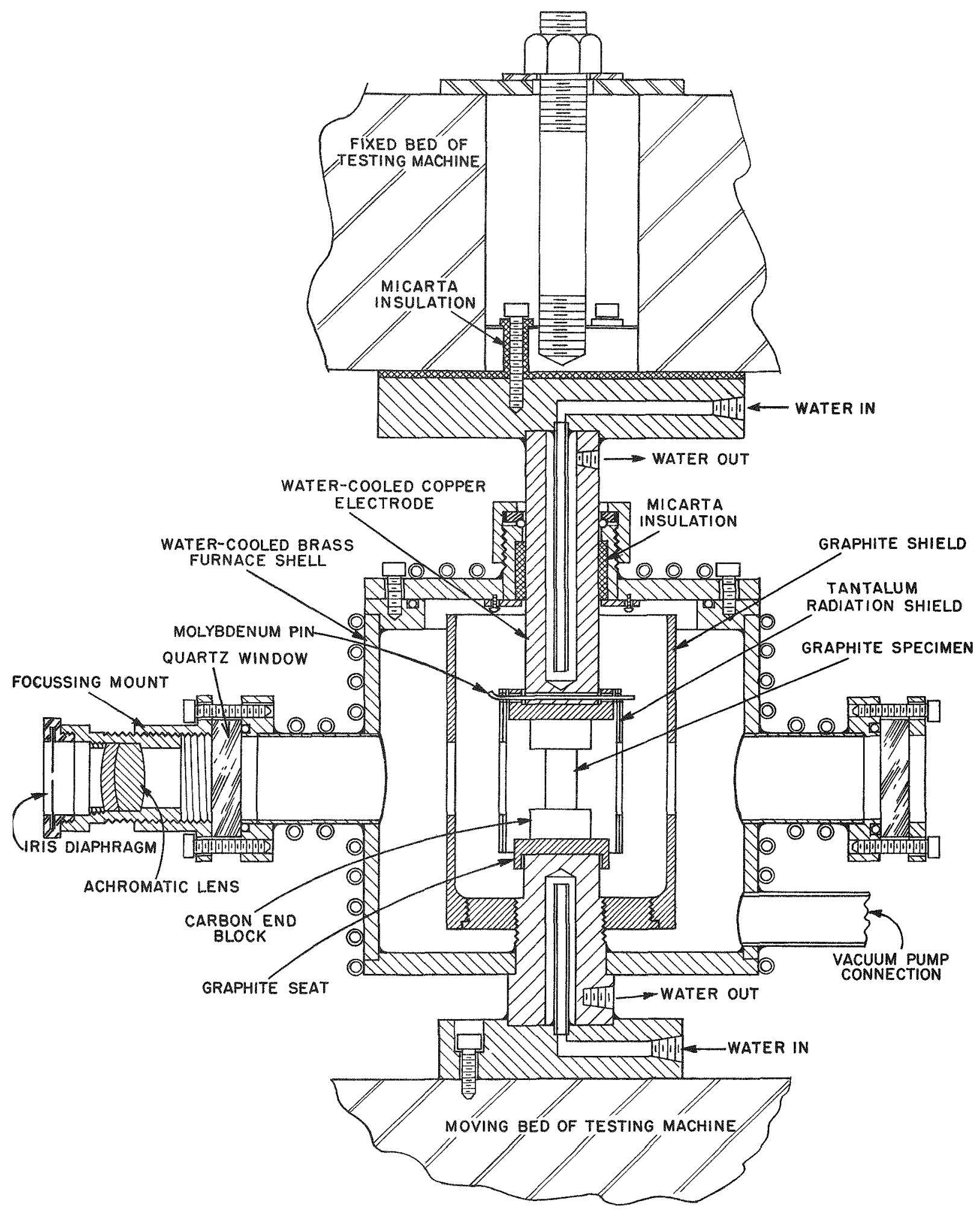

Figure 1. Cross Section of Compression Test Furnace. 


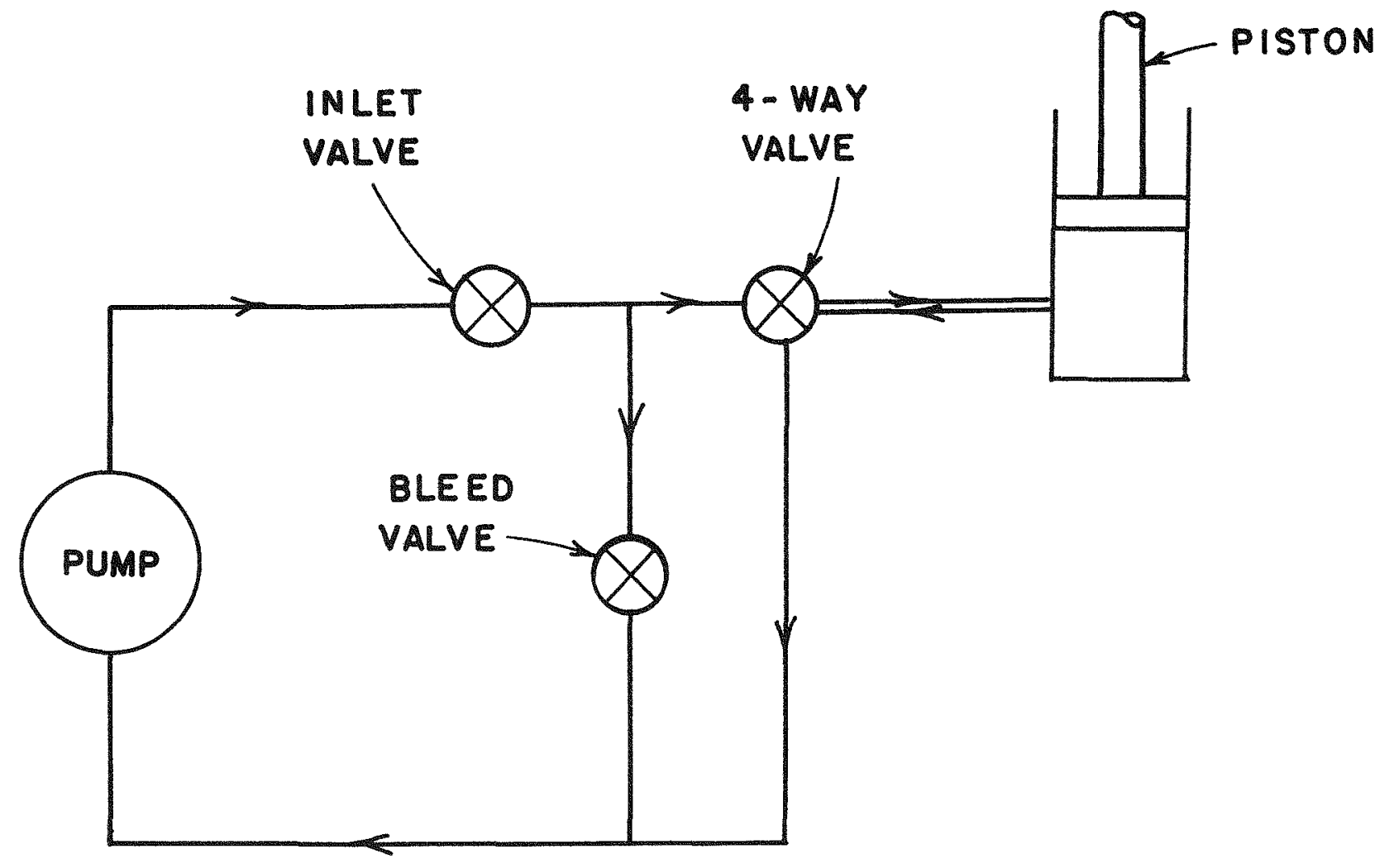

Figure 2. Schematic Dlagram of Hydraulic Loading System. 
11

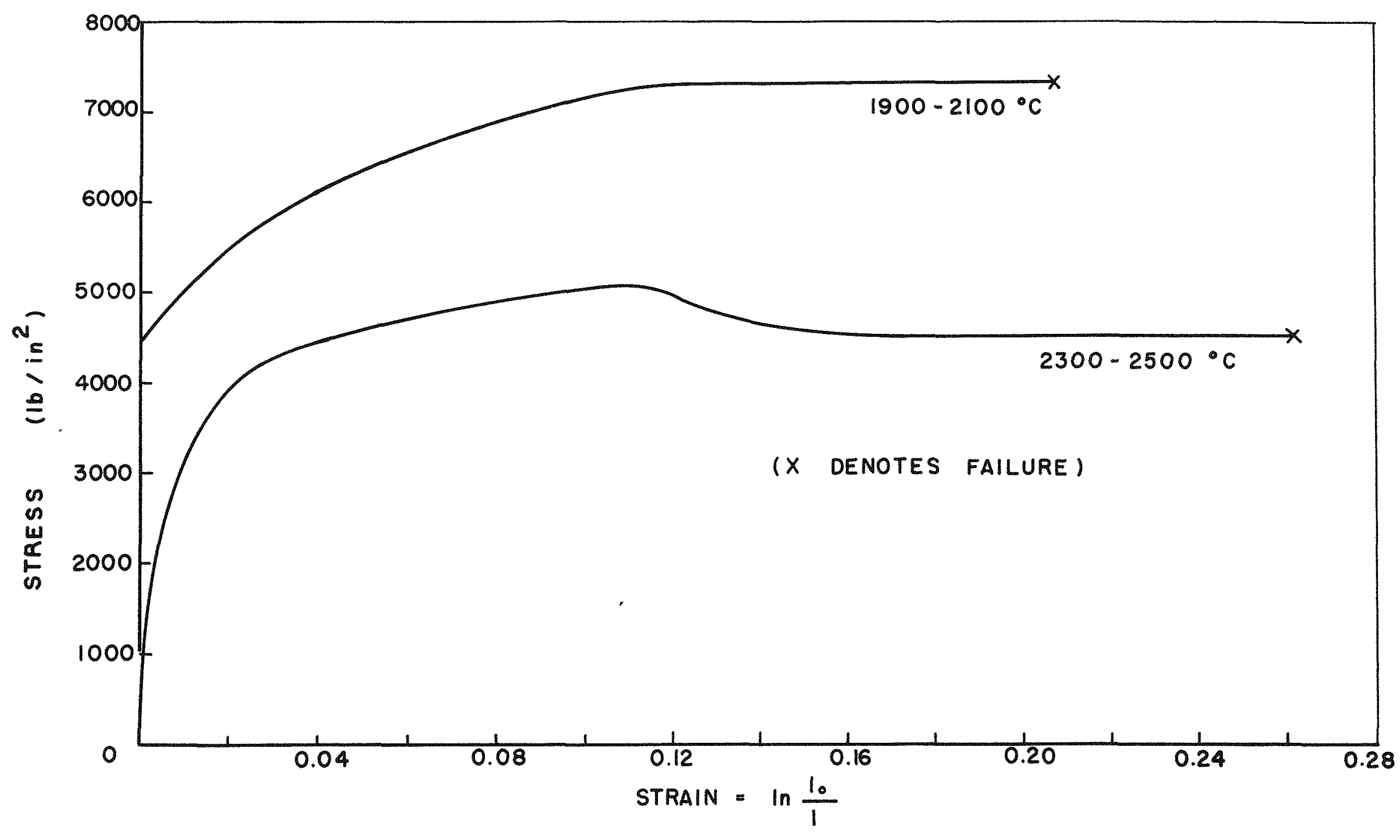

Figure 3. Stress-Strain Curves Obtained at Different Temperatures. 


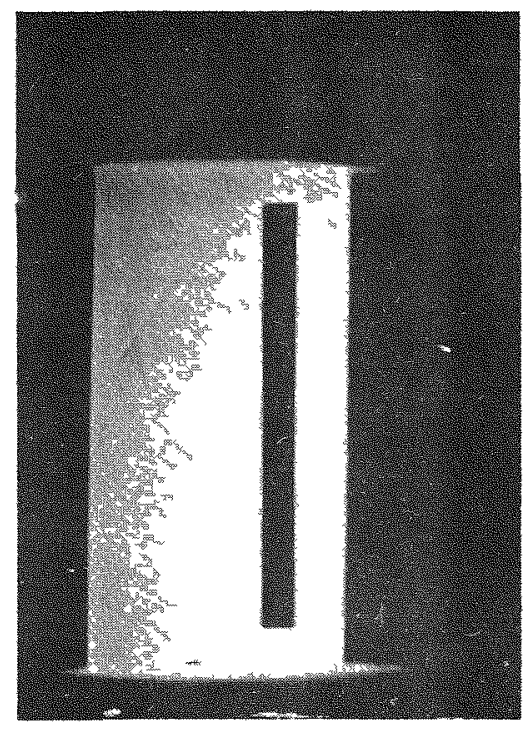

$\sigma \stackrel{0}{ }$

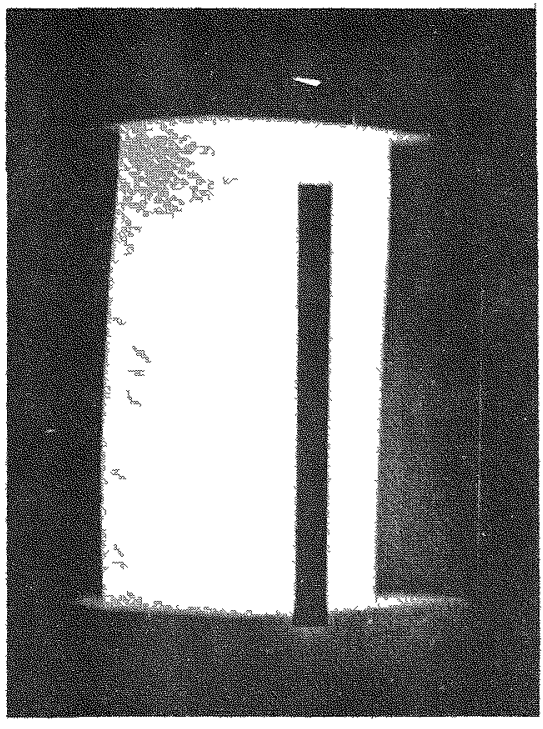

$\sigma=5100 \mathrm{psi}$

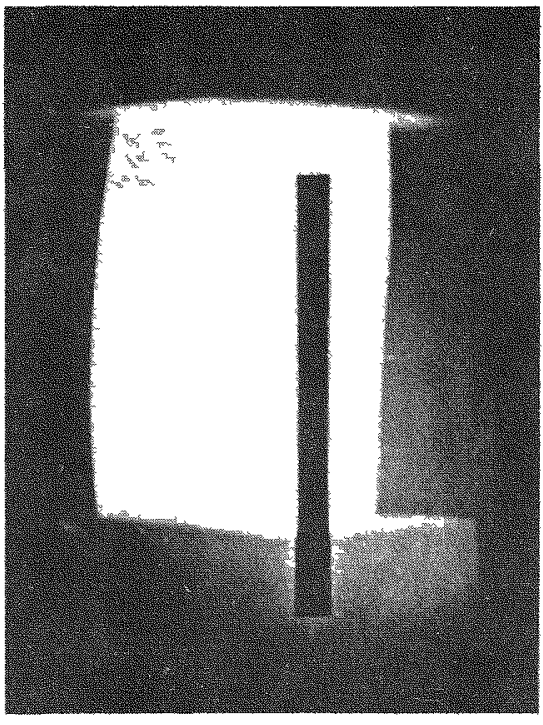

$\sigma=4530$ psi

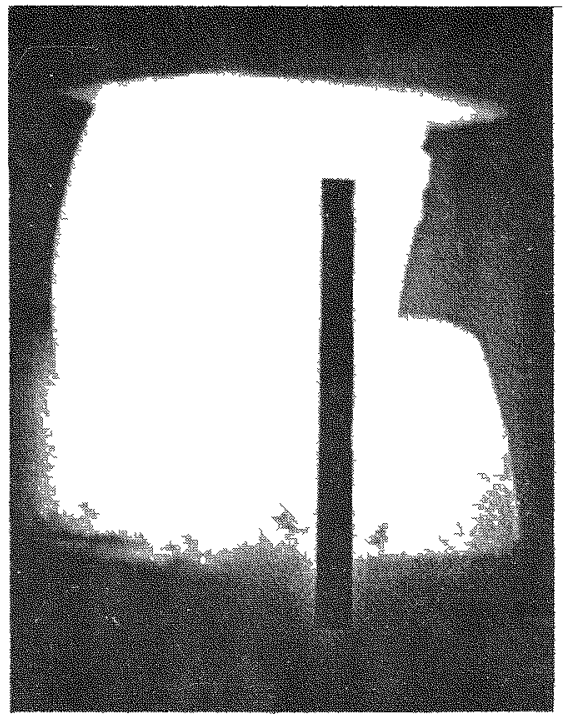

FAILURE

Figure 4. Stages in the Fracture of a Graphite Specimen in the Range $2300-25000^{\circ}$. 


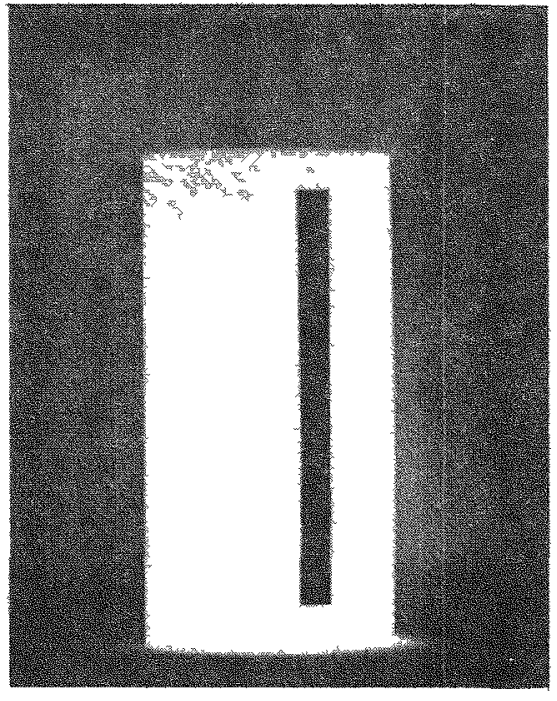

$\sigma \approx 0$

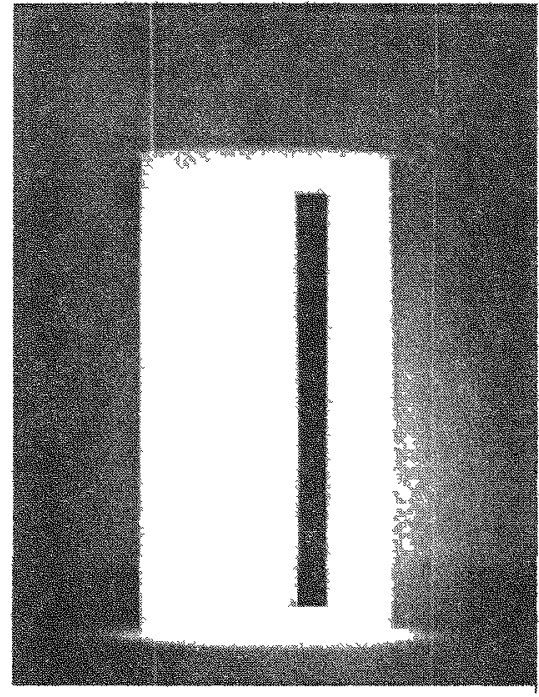

$\sigma=5050 \mathrm{psi}$

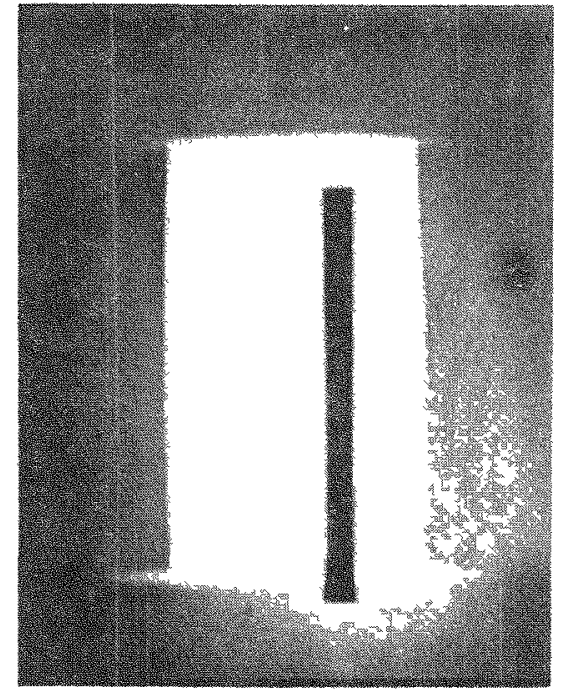

$\sigma=7350 \mathrm{psi}$

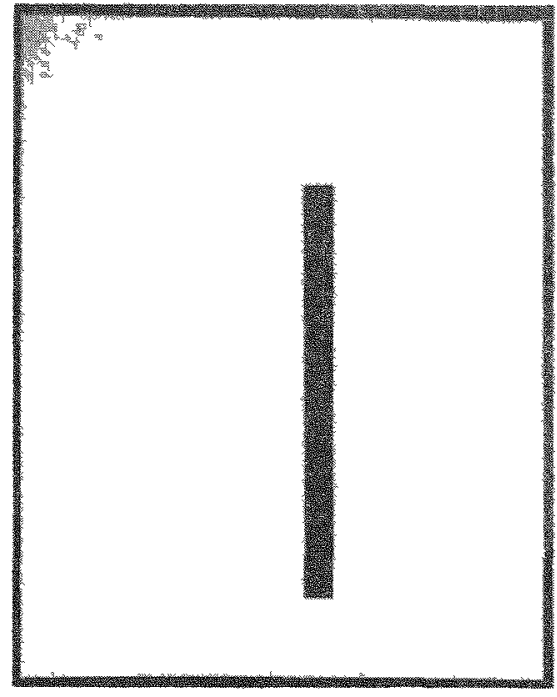

FAILURE

FIgure 5. Stages in the Precture of a Graphite Specimen In the Range 1900-21000 C. 


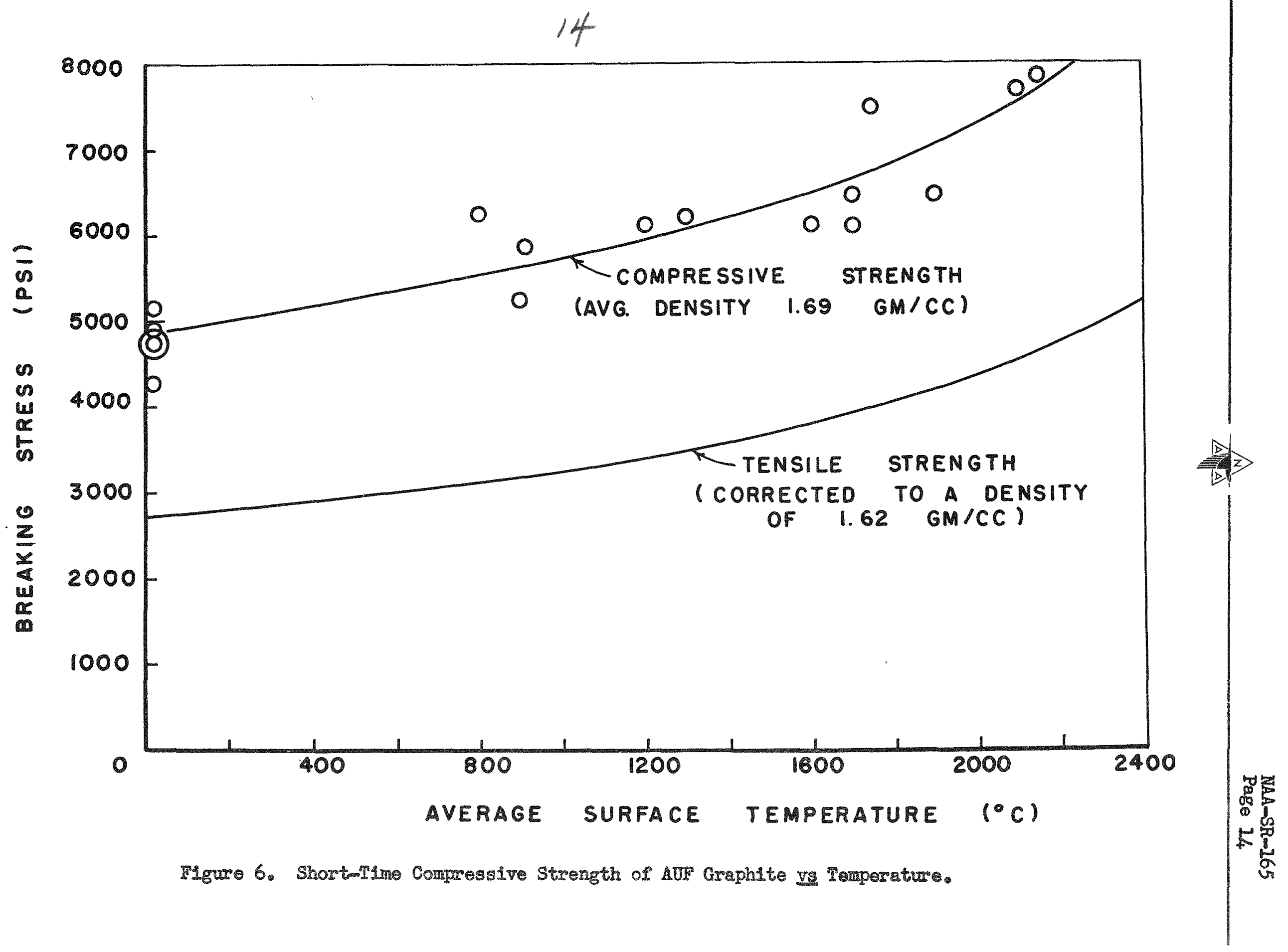




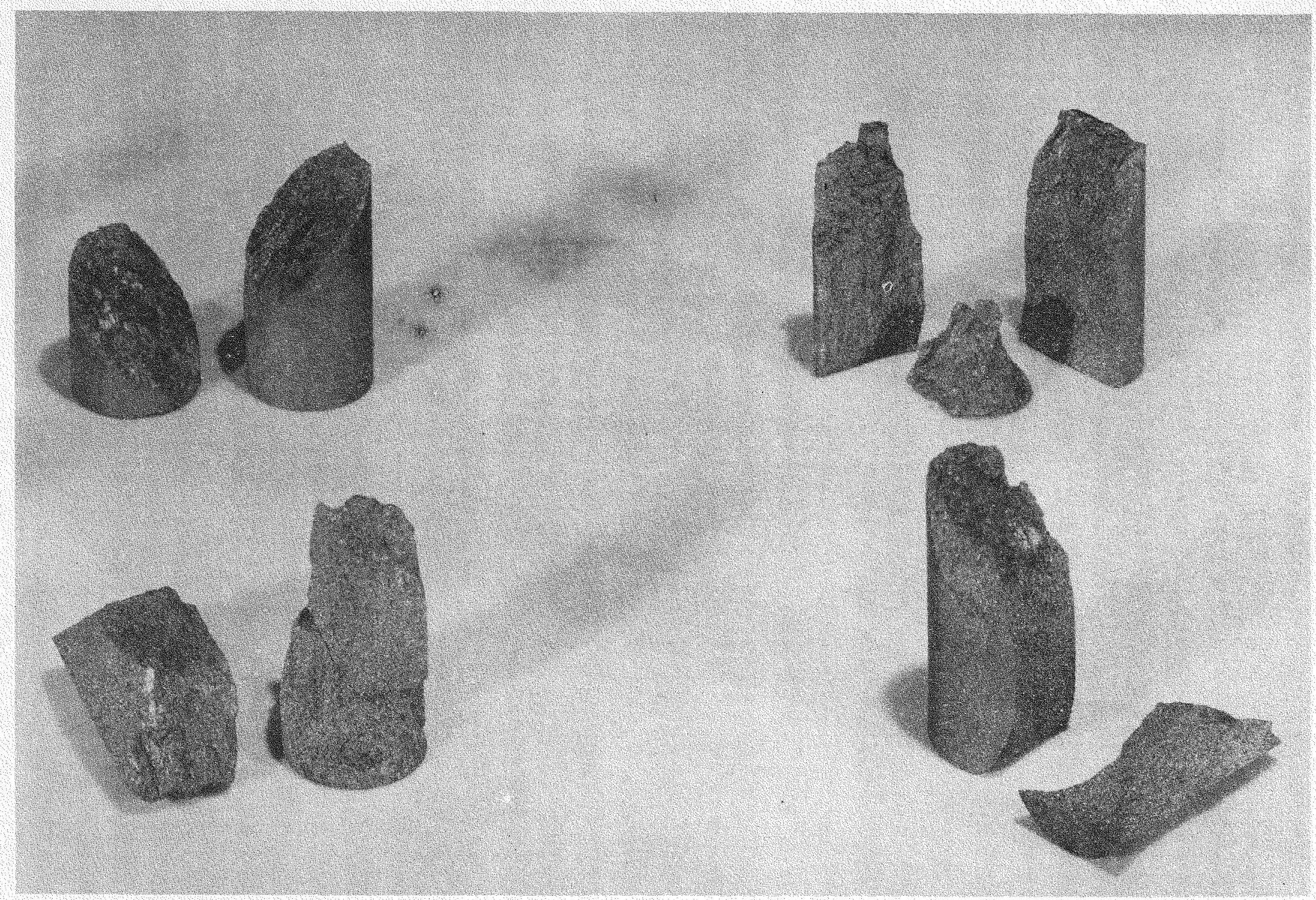

Figure 7. Typical Fractures Obtained in the Range 20-20000 C. 
FOKM 81 P-1

16
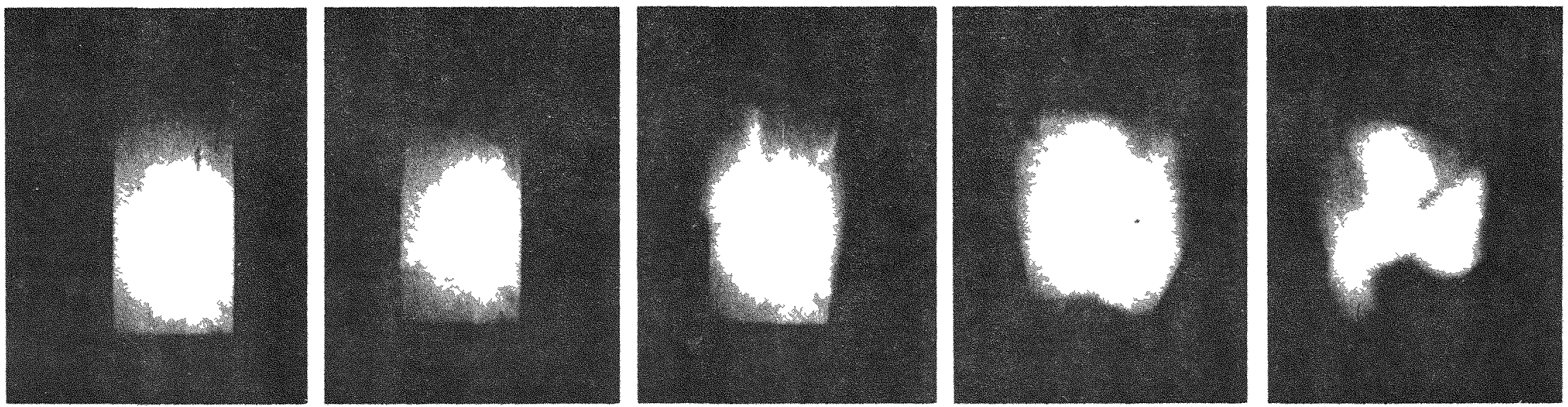

D2

Figure 8. Fracture of a Graphite Specimen at $2000^{\circ} \mathrm{C}$ (Consecutive Framea at About 1200 Frames/Sec). 

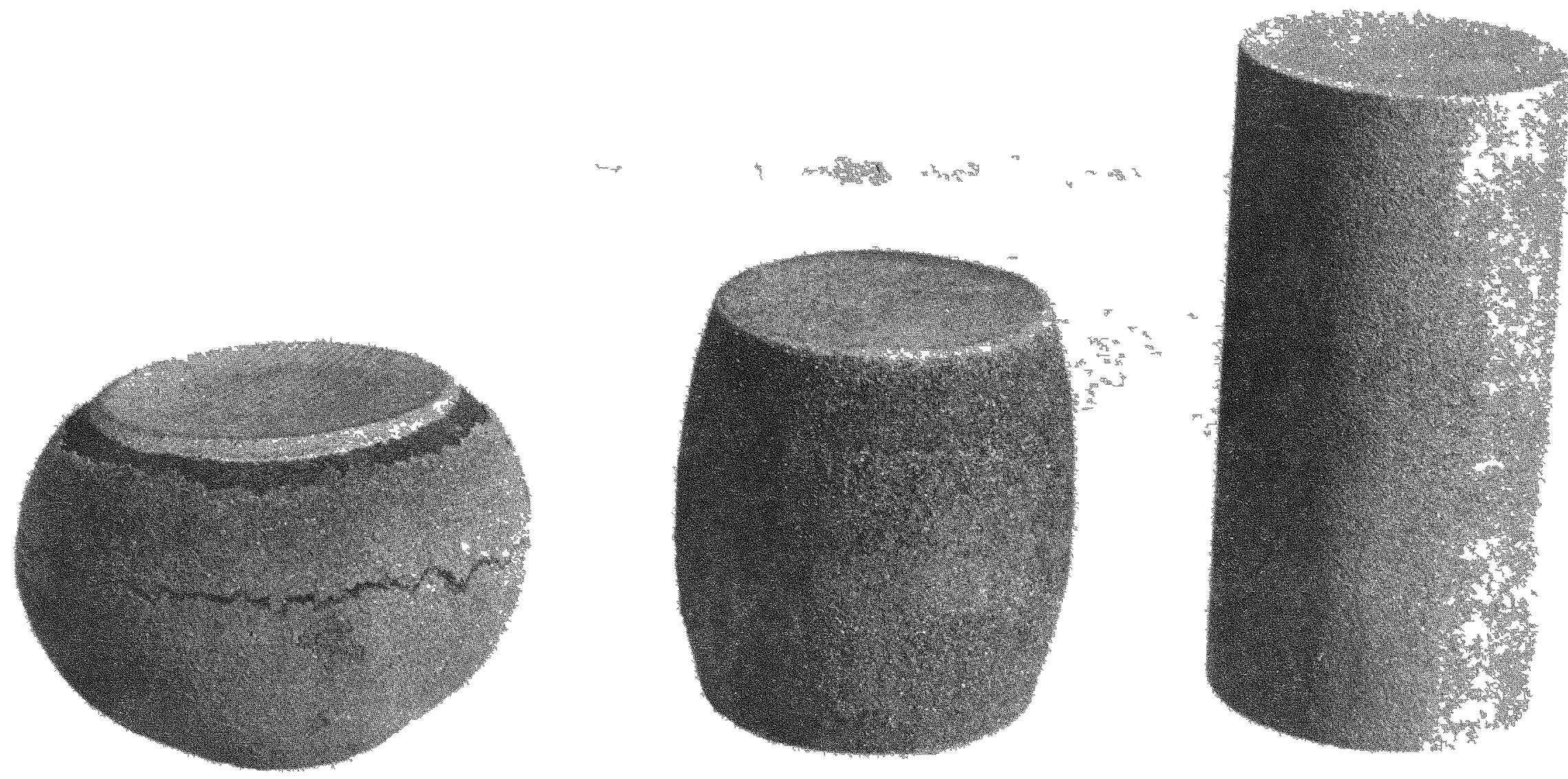

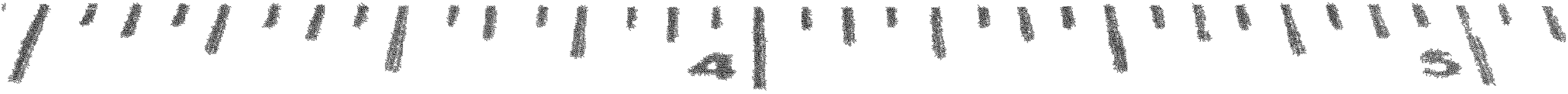

Figure 9. Specimens Compressed SLowy at Surface Temperatures of $26000^{6}$ and $2400^{\circ} \mathrm{C}$ (Irom Left) as Compared to Untested Specimen (Right). 


\section{REFERENCES}

I. Malmstrom, C. R., R. D. Keen and L. Green, Jr., "Some Mechanical Properties of Graphite at Elevated Temperatures," Journal of Applied Physics, 22, 593-600, (1951).

2. Faris, F. E., I. Green, Jr., and C. A. Smith, "Thermal Dependence of the Elastic Moduli of Polycrystalline Graphite," to be published in the Journal of Applied Physies.

3. Green, I., "The Behavior of Graphite Under Alternating Stress," to be published in the Journal of Applied Mechanics.

4. Nadai, A., Plasticity, McGraw-Hill Book Company, Inc. New York, 1931, p. 108 .

5. Miller, A. E., Personal Communication.

6. Herring, C., "Diffusional Viscosity of a Polycrystalline Solid," Journal of Applied Physics, 21, 437-445, (1950).

7. MeGee, J., Personal Communication. 